\title{
Ogrody Keplera - Ars Electronica 2020
}

\author{
SIDEY MYOO \\ Instytut Filozofii \\ Uniwersytet Jagielloński w Krakowie \\ Zakład Teorii Sztuki Mediów \\ Akademia Sztuk Pięknych w Krakowie
}

\begin{abstract}
Myoo Sidey, Ogrody Keplera - Ars Electronica 2020 [Kepler's Gardens - Ars Electronica 2020]. "Images" vol. XXIX, no. 38. Poznań 2021. Adam Mickiewicz University Press. Pp. 283-287. ISSN 1731-450X. DOI 10.14746/i.2021.38.19.

The article presents the content shown at the "Festival of Art, Science and Society - Ars Electronica 2020", which is organized annually in Linz. The focus was on the awarded and distinguished artistic works, taking into account their interpretation and the workshop in which they were created. In the article are presented i.a. such works of art as computer animation, network art, artificial intelligence art, hybrid art or bioart, which was briefly interpreted in relation to the currently being developed technologies and social contexts that accompanies it. The text was written as a result of the author's personal participation in the festival, which also allowed to take into account the differences between the festival held mostly by web, as it was in 2020, compared to the stationary participation in it, as it was in previous years.
\end{abstract}

KEYwords: Festival Ars Electronica, new media art, contemporary art, interactive media, electronic image, virtuality

Tegoroczny festiwal Ars Electronica został w znacznym stopniu usieciowiony. Dotyczyło to przygotowanych w celach prezentacyjnych dokumentacji prac, jak również streamowania szeregu wydarzeń. Świetnie przygotowano stronę Ars Electronica do przeniesienia wydarzeń do sieci, a Linz zupełnie nie przypominał tego miasta, do którego przez lata zjeżdżały zainteresowane Sztuką Nowych Mediów, cyberkulturą lub nowinkami technologicznymi tłumy $\mathrm{z}$ całego świata. W tym roku zaproponowano dodatkową formułę organizacyjną, polegającą na uwzględnieniu przebiegu akcji i prezentowaniu wystaw rozproszonych w różnych miastach na świecie. W tym celu wykorzystano tytuł tegorocznego festiwalu i poszerzono ideę Ogrodów Keplera „jako globalnej podróży mapującej nowy świat. Podróży, w którą to nie my wyruszamy, ale przemieszczają się nasze pomysły i projekty, istniejąc $\mathrm{w}$ globalnej sieci, w której my także się gromadzimy po to, by dyskutować o tym, co można zrobić" [1]. W tym rozproszonym i hybrydowym projekcie festiwa- lowym wzięło udział ponad sto miast, między innymi Barcelona, Bruksela, Tokio, Boston, Buenos Aires, Seul, Bazylea, Ateny, Johannesburg, Los Angeles, Amsterdam, Warszawa i Wrocław. Wykorzystano możliwości, jakie daje Facebook, Instagram i Twitter. W samym Linzu większość przestrzeni, w których prezentowano prace artystyczne, w poprzednich latach była nieczynna, jedynie Uniwersytet Johanna Keplera przypominał o czasach sprzed pandemii. W uniwersyteckich ogrodach i w samym budynku zorganizowano wystawy i uroczystości, ale te ostatnie gromadzily zaledwie kilka lub kilkanaście osób. Big Concert Night odbył się w całkiem kameralnych warunkach, praktycznie bez udziału odbiorców. Działało, jak co roku, Centrum Kultury Współczesnej: OK Offenes Kulturhaus, w którym pokazano prace nagrodzone Golden Nica (10 tys. euro) i prace wy-

[1] Strona Ars Electronica „Ogrody Keplera”: $<$ https://ars.electronica.art/keplersgardens/en/>. 
różnione oraz te, którym przyznano nagrodę Komisji Europejskiej Start Prize (40 tys. euro).

$\mathrm{W}$ tym roku przyznano nagrody w pięciu kategoriach: Computer Animation, Digital Communities, Interactive Art+, u19 Create Your World oraz Visionary Pioneers of Media Art. Golden Nica w pierwszej z wymienionych kategorii otrzymała Miwa Matreyek za performowany film Infinitely Yours[2]. Ta trwająca 25 minut akcja tworzona była przez dwie projekcje, z których pierwsza służyła pokazowi filmu, a druga, tylna, oświetlała artystkę wykonującą za ekranem baletowy performance. Całość tworzyła przestrzenną formę, gdzie cień artystki plastycznie kontrastował, ale i płynnie wplatał się w treść filmu, nadając mu dodatkowe znaczenie. Tematyka była ekologiczna, budząca skojarzenia z Koyaanisqatsi Godfreya Reggio, co również można wyczytać w wypowiedzi artystki: „Opowiadam historie o świecie ludzi (ludzkości) i przyrody poprzez metaforyczne doświadczenia. Pragnę, aby moja praca była katalizatorem dialogu, odnosząc się do bieżących wydarzeń i rzucając odbiorcy wyzwanie, aby spojrzał on na świat inaczej i poprzez symboliczne obrazy emocjonalnie"[3]. Wyróżnienie w tej kategorii otrzymała Maja Gehrig za found footage Average Happiness, w którym pokazano znaczenie zmienności pewnych założonych parametrów wpływających na wyobrażony stan zadowolenia społeczeństwa w różnych częściach świata. Kolejne wyróżnienie otrzymał film opisujący niezwykłe miejsce, jakim jest enklawa hiszpańska Bab Sebta niedaleko Ceuty - port, targ, miejsce przerzutowe - na wybrzeżu afrykańskim. Filmowej rekonstrukcji zdarzeń, połączonych $\mathrm{z}$ wywiadami osób codziennie tam pracujących, dokonała Randa Maroufi.

[2] H. Leopoldseder, Ch. Schopf, G. Stocker, CyberArts 2020 - Prix Ars Electronica 2020, Berlin, s. 23-25, <https://ars.electronica.art/keplersgardens/files/2020/o9/cyberarts2020.pdf>, dostęp: 9.02.2021.

[3] Strona Ars Electronica „Winners”: <https:// ars.electronica.art/prix/en/winners/computer-animation/>, dostęp: 9.02.2021. Tłum. własne.
W kategorii Interactive Art+ główną nagrodę otrzymała Lauren Lee McCarthy za pracę z zakresu sztuki monitoringu, zatytułowaną Someone (2019). Zaprezentowano tu dokumentację akcji, która odbyła się w 2019 roku i polegała na umieszczeniu w Galerii Hudson 205 w Nowym Jorku czterech stanowisk z wyświetlaczami, na których pokazano prywatne mieszkania osób uczestniczących w projekcie. Instalacja dotyczyła idei ciągłego zapośredniczenia do sieci poprzez kamery wraz z elementami interaktywności, co wiązało się z możliwością nawiązania kontaktu odbiorców z mieszkańcami. Pierwsze wyróżnienie w tej kategorii otrzymał Simon Weckert za intrygującą pracę Google Maps Hacks (2020), a drugie Lynn Hershman Leeson za Shadow Stalker (20182021), która dotyczyła tematyki powszechnej inwigilacji. Szczególnie zainteresowała mnie pierwsza $\mathrm{z}$ wymienionych, idiosynkratyczna praca, zawierająca, moim zdaniem, pewnego rodzaju sprzeczność. Wynika to $\mathrm{z}$ fakeowego wykorzystania Google Maps, co polegało na zgromadzeniu 99 smartfonów na ciągniętym przez artystę wózku po podmiejskich ulicach, co generowało informację dla gps, że na danej ulicy, która w rzeczywistości była pusta, jest właśnie korek. Moje wątpliwości wiążą się z pytaniem o warstwę konceptualną powyższej pracy, gdyż tego rodzaju manipulacyjne działanie, które, jak widać, jest możliwe, nie wiadomo czemu w tym przypadku miałoby służyć. Pokazanie, że Google Maps został oszukany w tak mało sensowny sposób, nic konstruktywnego nie wnosi. Zawarta w pracy krytyczna refleksja dotycząca „ślepoty” Google Maps jest wykreowaną z premedytacją sytuacją, która w nieokreślony sposób ma się do rzeczywistych sytuacji na drodze, nie mówiąc o pożyteczności tej technologii, którą trudno jest przecenić, a co dopiero próbować krytykować.

W kategorii Digital Communities nagrody otrzymały trzy podobne pod względem warsztatowym rozproszone prace sieciowe. Golden Nica przypadła anonimowej grupie twórców, jak można wnosić - z Hongkongu, za interwencyjną i wciąż działającą pracę Be Water by Hong Kon- 
gers (2019). Poddaje się w niej krytyce społecznej narzucane prawodawstwo z Chin, w szczególności prawo o ekstradycji, które zagroziło niezależności sądów tego regionu. Pierwsze z wyróżnień honorowych otrzymała organizacja społeczna Algorithmic Justice League za pracę podającą w wątpliwość coraz bardziej rozprzestrzeniającą swoje działanie sztuczną inteligencję: „W dzisiejszym świecie systemy sztucznej inteligencji są wykorzystywane do decydowania o tym, kto zostanie zatrudniony, o jakości otrzymywanego leczenia i czy staniemy się podejrzanymi w dochodzeniu policyjnym" [4]. Drugie wyróżnienie przypadło libańskiej organizacji społecznej Habaq za pracę dotyczącą interaktywności społecznej nakłaniającej do „uprawiania żywności w przestrzeni publicznej-czyniąc je otwartymi i dostępnymi dla całej społeczności”[5]. Te trzy prace łączy daleko idące usieciowienie, co powodowało, że charakterystyczny dla nich, znajdujący się w przestrzeni wystawienniczej komputer, był centralnym elementem prezentacji, bez którego informacja o aktywistycznej działalności tych organizacji byłaby niemożliwa. Dodatkowo dookoła rozwieszono tekstowe i graficzne informacje dotyczące tych prac, co sprawiało wrażenie, jakby sztuka sieci szukała wsparcia poprzez zagospodarowanie przestrzeni fizycznej. Zainteresowała mnie ta sytuacja wystawiennicza, gdzie nie chodziło o hybrydyzację dwóch rzeczywistości, ale o to, że przestrzeń fizyczna jest przedsionkiem do wejścia do rzeczywistości elektronicznej, by uzyskać realną, prawdziwą informację o tych pracach. Przestrzeń fizyczna wydała się wręcz niezdarnie zaaranżowana za pomocą naklejonych na ścianę plakatów lub krótkich informacji pisanych, w których próbowano przekazać to, co w pełnej wartości przekazu istnieje tylko w sieci.

W kategorii u19 Create Your World główną nagrodę otrzymała grupa twórców: Lisa Rass, Franziska Gallé, Jona Lingitz, Anna Fachbach, za dobrze zrobiony techniką poklatkową, malowniczy film Samen. W kategorii Visionary Pioneer of Feminist Media Art nagrodę za dorobek artystyczny przyznano Golden Nica Valie Export (Waltraud Lehner), artystce z nur- tu krytycznego i interwencyjnego, która „Jest jedną z najważniejszych i odnoszących sukcesy pionierek feministycznej sztuki mediów na świecie" [6].

Start Prize: Grand Prize - Innovative Collaboration, która honoruje innowacyjność współpracy pomiędzy przemysłem lub jakimś rodzajem technologii i sztuką, otrzymała Olga Kisseleva za pracę EDEN - Ethics - Durability Ecology - Nature: When a Tree became a Partner (2018). Drugą nagrodę Grand Prize - Artistic Exploration, honorującą artystyczne poszukiwania i takie prace, które mają znaczący wpływ na sposób wykorzystania lub postrzegania technologii, otrzymała Andrea Ling za pracę Design by Decay, Decay by Design (2018). Pierwsza z prac dotyczy roślin, „[...] które komunikują się ze swoim środowiskiem. Zamiast słów używają różnych rodzajów emisji molekularnej. Komunikacja może być nawiązana pomiędzy drzewami tego samego gatunku, ale może też być adresowana do innego organizmu: owada lub zwierzęcia - w tym człowieka" [7]. W pracy tej wykorzystano telefoniczną sieć komórkową do komunikacji pomiędzy roślinami na różnych kontynentach. Efektu tej komunikacji mogli doświadczyć odbiorcy, mając do dyspozycji jej zwizualizowany obraz. Z kolei Design by Decay, Decay by Design to praca, w której przedmiotem zainteresowania jest biodegradowalność - projektowanie odpowiednich procesów, które ją umożliwiają, i poszerzanie tego procesu na nowe produkty: „[...] celem było zorganizowanie rozkładu przy użyciu enzymów, grzybów, bakterii i innych środków biologicznych, jako sposobów jednoczesnego

[4] Strona Algorithmic Justice League: <https://www. ajl.org/>, dostęp: 9.02.2021.

[5] Strona Ars Electronica „Winners”: <https://ars. electronica.art/prix/en/winners/digital-communities/>, dostęp: 9.02.2021.

[6] Strona Ars Electronica „Winners”: <https://ars. electronica.art/prix/en/winners/visionary-feminist/>, dostęp: 9.02.2021.

[7] Praca ta była prezentowana na WRO 2019, skąd pochodzi powyższy cytat: <http://wro2019.wrocenter. pl/works/eden/>, dostęp: 9.02.2021. 
rozkładu i komponowania materii biologicznej. Pośrednicząc w rozkładzie poprzez dobór gatunków, kontrolę warunków środowiskowych i tworzenie szablonów składników odżywczych, aktywnie dążę do zmiany, jako pożądanej jakości w świecie fizycznym, a także gwarantuję, że mechanizmy konstruktywnej odnowy będą mogły być szerzej zastosowane" [8].

Wśród prezentowanych prac w Uniwersyteckim Ogrodzie moje zainteresowanie wzbudziła kopuła Laboratorium Fulldome, nad którą prace prowadzone są na Wydziale Sztuki Cyfrowej Uniwersytetu Sztuk Stosowanych w Wiedniu. Prezentowano w niej immersyjne filmy za pomocą czterokanałowej projekcji. Ta już historyczna technika projekcyjna, poddana niejeden raz eksperymentom, chociażby w znajdującej się przez lata CAVE w Ars Electronica Center, która w ostatnich latach została tam zastąpiona wielofunkcyjną przestrzenią projekcyjną Deep Spce (4k), robiła wrażenie dzięki zastosowaniu „kroczącej” animacji, w której wykorzystano ruch skierowany do środka kopuły, w ten sposób oddziałując na odbiorcę. Przekonująco wyglądało na przykład „wypełnianie” się kopuły wodą, zwłaszcza gdy na końcu widać było na sklepieniu niewielki, niezapełniony wodą prześwit lub w innej animacji "tłoczące się" i przemieszczające się do centrum kopuły fragmenty miejskiej zabudowy. Znajdujący się w kopule odbiorcy podporządkowani byli pandemicznym wymogom, niemniej kopuła wzbudzała powszechne zainteresowanie i pomimo odczuwalnej duchoty powietrza, cały czas była pełna osób. Kolejną interesująca pracą była instalacja nawiązująca do rzeczywistości wirtualnej, autorstwa Alexandry Ginsberg, Machine Auguries [9] (2019). Zastosowano w niej dwie sieci

[8] Strona Ars Electronica "Starts Prize": <https:// starts-prize.aec.at/en/design-by-decay/>, dostęp: 9.02.2021.

[9] A. Ginsberg, Machine Auguries, <https:// www.daisyginsberg.com/work/machine-auguries>, dostęp: 9.02.2021.

[10] Strona Ars Electronica Alexandra Ginsberga, Machine Auguries, <https://www.daisyginsberg. com/work/machine-auguries >, dostęp: 9.02.2021. neuronowe, które uczyły się śpiewu ptaków, wykorzystując: „[...] nagrania pierwiosnków, sikorek bogatek, pleszek, rudzików, drozdów i chórów śpiewających o świcie" [10]. To kolejny przykład zastępowania tego, co fizyczne, przez wirtualne, z tym, że wirtualne podlega dalszej, wewnętrznej ewolucji, nie tylko powielając wzorzec, ale go aproksymując, przez co zaczyna się liczyć sam śpiew ptaków, a nie śpiew ptaków biologicznych. Przykład ten może służyć interpretacji idącej w kierunku transhumanistycznym, mówiącej, że ludzka ekspansja z jednej strony może powodować niszczenie lub degradację naturalnego środowiska, a z drugiej służyć zapamiętywaniu i rozwijaniu przynależnych do niego zjawisk. Tego rodzaju prace artystyczne, zawierające powyższą bimodalność, wskazują na nieuchronny proces powiększania antropoceńskiego artefaktu, w którym to procesie powinno się uwzględniać wartość i zanikanie świata fizycznego. Podobną w wymowie była prezentowana w Uniwersyteckim Ogrodzie Keplera praca robodrum autorstwa Johannesa Braumanna, Amira Bastana i Martina Schwaba. Odbiorca miał do dyspozycji kontroler perkusyjny midi pad, na którym mógł wygrać kilkutaktową perkusyjną sekwencję, a następnie jeden z czterech robotów podejmował ten rytm. $\mathrm{W}$ rozmowie dowiedziałem się, że jak na razie nie wykorzystano tych perkusistów podczas koncertu, ale ze względu na perfekcyjność gry i przesunięcie fizycznych granic użycia perkusji, może okazać się dobrym rozwiązaniem.

Polskim akcentem była współautorska praca Folded Maps of Time, powstała pod egidą Instytutu Adama Mickiewicza - koncert wykonany w Warszawie w ramach umiędzynarodowienia Ogrodów Keplera, których autorem był kompozytor i wykonawca muzyki elektroakustycznej Marek Chołoniewski i perkusista z Wielkiej Brytanii Chris Cutler, z asystą Piotra Madeja i Artura Lisa. Koncert wykorzystywał efekt biofeedbacku, dzięki którym wybrzmiewająca muzyka modyfikowana była stanami mózgu uczestniczących w koncercie muzyków. Drugim akcentem była praca autorstwa Pawła Janickiego, zaprezentowana również w ramach 
Ars Electronica Gardens, zatytułowana Point Nemo: „[...] geograficznego konstruktu, wyznaczonego na Oceanie Spokojnym miejsca możliwie najodleglejszego od wszystkich lądów, nazywanego często biegunem niedostępności"[11]. Jedną ze składowych Point Nemo był performans Noumen Point, w którym wykorzystano połączenie urządzeń mobilnych odbiorców, łączących się ze stroną w sieci, co sprawiło, że urządzenia te wybrzmiewały przygotowanymi na stronie dźwiękami. Ta interesująca praca ma zakotwiczenie w filozofii, w Kantowskiej idei noumenów, o których można domniemywać jako istniejących transcendentnie, po których pozostaje co najwyżej ślad w ludzkim, fenomenalnym umyśle. Warto także wspomnieć o kontynuowaniu przez polskich twórców i twórczynie z Poznańskiego Centrum Superkomputerowo-Sieciowego współpracy w międzynarodowej grupie z Linzu, Immersify.

Ars Electronica to w części także spotkania z osobami, z którymi nie ma sposobności się zobaczyć podczas całego roku dzielącego kolejne edycje Festiwalu. Mam nadzieję, że ten aspekt powróci wraz z powracającymi do Linzu zainteresowanymi Ars Electronica uczestnikami w 2021.
B I B L I O G R A F I A

Ginsberg A., Machine Auguries, <https://www.daisyginsberg.com/work/machine-auguries $>$

Leopoldseder H., Schopf Ch., Stocker G., CyberArts 2020 - Prix Ars Electronica 2020, Hatje Cantz, Berlin, s. 23-25, <https://ars.electronica.art/keplersgardens/files/2020/09/cyberarts2020.pdf>, dostęp: 9.02.2021

STRONY Z W I A Z A NE Z FEST I WA LEM

Ars Electronica „Ogrody Keplera”: < https://ars.electronica.art/keplersgardens/en/>, dostęp: 9.02.2021

Ars Electronica „Winners”: <https://ars.electronica.art/ prix/en/winners/computer-animation/>, dostęp: 9.02.2021

Algorithmic Justice League: <https://www.ajl.org/>, dostęp: 9.02.2021

Ars Electronica „Winners”: <https://ars.electronica.art/ prix/en/winners/digital-communities/>, dostęp: 9.02.2021

Ars Electronica „Winners”: <https://ars.electronica. art/prix/en/winners/visionary-feminist/>, dostęp: 9.02.2021

Ars Electronica "Starts Prize": <https://starts-prize.aec. at/en/design-by-decay/>, dostęp: 9.02.2021

WRO 2019: <http://wro2019.wrocenter.pl/works/eden/>, dostęp: 9.02.2021

WRO 2020: <https://wrocenter.pl/pl/point-nemo/>, dostęp: 9.02 .2021

[11] Strona WRO 2020: <https://wrocenter.pl/pl/ point-nemo/>, dostęp: 9.02.2021. 